\title{
Efficacy of preventive endoscopic balloon dilation for esophageal stricture after endoscopic resection.
}

\section{AUTHOR(S):}

Ezoe, Yasumasa; Muto, Manabu; Horimatsu, Takahiro; Morita, Shuko; Miyamoto, Shin'ichi; Mochizuki, Satoshi; Minashi, Keiko; Yano, Tomonori; Ohtsu, Atsushi; Chiba, Tsutomu

\section{CITATION:}

Ezoe, Yasumasa ... [et al]. Efficacy of preventive endoscopic balloon dilation for esophageal stricture after endoscopic resection.. Journal of clinical gastroenterology 2011, 45(3): 222-227

\section{ISSUE DATE:}

2011-03

URL:

http://hdl.handle.net/2433/156435

\section{RIGHT:}

(c) 2011 Lippincott Williams \& Wilkins, Inc.; この論文は出版社版であり ません。引用の際には出版社版をご確認ご利用ください。; This is not the published version. Please cite only the published version. 
1 Efficacy of preventive endoscopic balloon dilation for esophageal

2 stricture after endoscopic resection

3

4 Yasumasa Ezoe, M.D. ${ }^{1}$, Manabu Muto, M.D., Ph.D. ${ }^{2}$, Takahiro Horimatsu, M.D. ${ }^{2}$, Shuko

5 Morita, M.D. ${ }^{2}$, Shin'ichi Miyamoto, M.D., Ph.D. ${ }^{2}$, Satoshi Mochizuki, M.D. ${ }^{3}$, Keiko Minashi,

6 M.D. ${ }^{3}$, Tomonori Yano, M.D. ${ }^{3}$, Atsushi Ohtsu, M.D., Ph.D. ${ }^{3}$, Tsutomu Chiba, M.D., Ph.D. ${ }^{2}$

7

$8{ }^{1}$ Department of Multidisciplinary Cancer Treatment, Kyoto University, Kyoto, Japan

$9 \quad{ }^{2}$ Department of Gastroenterology and Hepatology, Kyoto University, Kyoto, Japan

$10 \quad{ }^{3}$ Division of Digestive Endoscopy and Gastrointestinal Oncology, National Cancer Center

11 Hospital East, Kashiwa, Japan

12

13 Corresponding author:

14 Yasumasa Ezoe

15 54 Kawara-cho, Shogoin, Sakyo-ku, Kyoto 606-8507, Japan

16 e-mail: yasuzoe@kuhp.kyoto-u.ac.jp

17 telephone: +81-75-751-4319

18 Fax: +81-75-751-4303

19

20 Disclosures of potential conflicts of interest: none

21

22 Acknowledgement: none 


\section{ABSTRACT}

2 Background and Aim: We previously reported that mucosal defect involving over

3 three-fourths of the circumference of the esophagus after endoscopic mucosal resection

4 (EMR) is a risk factor for the development of the stricture. Although endoscopic balloon

5 dilation $(\mathrm{EBD})$ is a useful procedure to relieve the stricture, there is no standard strategy for

6 preventing development of the stricture. The aim of this study was to evaluate the efficacy

7 and the safety of preventive EBD.

8 Methods: From 1993 to 2008, 41 consecutive patients with extensive mucosal defect

9 involving over three-fourths of the esophageal circumference after EMR or endoscopic

10 submucosal dissection (ESD) were investigated. Preventive EBD was performed for 29 cases

11 within one week just after EMR/ESD and was repeated once a week until the mucosal defect

12 was completely healed. The remaining 12 cases were not underwent preventive EBD and

13 used as a historical control. If post-EMR/ESD stricture developed regardless of preventive

14 EBD, conventional EBD was given repeatedly until the stricture was completely relieved.

15 Results: Preventive EBD decreased the incidence of stricture [59\% vs 92\%, $\mathrm{p}=0.04$ ],

16 reduced the severity of stricture $[(\leq 2 \mathrm{~mm} ;>2 \mathrm{~mm}$ and $\leq 5 \mathrm{~mm} ;>5 \mathrm{~mm})=(1 ; 2 ; 14) \mathrm{vs}(4 ; 4 ; 3)$,

$17 \mathrm{p}=0.01]$ and shortened the duration required for resolving the stricture [29 days vs 78 days,

$18 \mathrm{p}=0.04]$ even when stricture developed. There was no complication associated with

19 preventive EBD procedure.

20 Conclusions: Preventive EBD is an effective procedure to prevent post- EMR/ESD stricture.

21 Preventive EBD should be considered when EMR/ESD results in a mucosal defect with a

22 circumference greater than three-fourths of the esophageal lumen.

24 Keywords: endoscopic mucosal resection; endoscopic submucosal dissection; esophageal 
1 stricture; endoscopic balloon dilation; prevention

2

\section{INTRODUCTION}

Endoscopic mucosal resection (EMR) is being increasingly accepted as one of the standard treatment for superficial esophageal cancer because of its minimal invasiveness and excellent survival rate.[1, 2] Furthermore, the endoscopic submucosal dissection (ESD) technique has made it possible to perform en-bloc resection of wide-spread neoplasia, such as a superficial spreading-type of esophageal squamous cell carcinoma and Barrett's esophageal cancer.[3-7] However, extended removal of the esophageal mucosa frequently causes severe stricture.[8, 9]

Esophageal stricture may markedly interfere with the oral intake of food and fluids, and thus affect the patients' quality of life adversely. In addition, once severe esophageal stricture has developed, it is difficult to resolve the condition. While endoscopic balloon dilation (EBD) is usually indicated for benign stricture including the cicatricial stricture caused by EMR/ESD, the effect of EBD is sometimes only temporary and the stricture would reappear. $[10,11]$

Before 2002, we performed EBD only when the patients complained of dysphagea by post-EMR/ESD stricture, and EBD was repeated until the dysphagea was completely resolved. In 2003, we reported that mucosal defects greater than three-fourths of the circumference of the esophagus after EMR are at high risk of developing esophageal stricture. [12] Since then, we started preventive EBD not to develop stricture, before post-EMR/ESD mucosal defects develop scarring.

In this study, we evaluated the effectiveness of preventive EBD for the patients with superficial widespread esophageal cancer who developed mucosal defect extending more 
1 than three-fourths of the circumference of the esophagus by EMR/ESD.

2

3 PATIENTS AND METHODS

\section{Patients}

From February 1993 to June 2008, we experienced 64 consecutive patients with

6 widespread mucosal defects greater than three-fourths of the esophageal circumference as a

7 result of EMR/ESD for esophageal cancer. Written informed consent was obtained from all

8 patients before performing EMR/ESD and EBD.

\section{Endoscopic resection technique}

To remove the lesions endoscopically, EMR [13, 14] or ESD [5-7] were performed.

\section{EBD technique}

All patients received administration of $17.5-35 \mathrm{mg}$ of pethidine hydrochloride in order to reduce the suffering from EBD procedure. All EBD procedure was performed using direct visualization and fluoroscopic monitoring. The balloon was positioned across the stenotic site, and then it was inflated carefully with double-diluted contrast agent. During the procedure, patients were closely observed with pulse, blood pressure, and oxygen saturation. When a patient experienced pain during the dilation or when a notch of the balloon placed on the stricture was gradually disappeared, dilation was stopped, and then the balloon was maintained in its inflated state and held close to the tip of the endoscope, and was pushed through the stenotic site like a bougie technique. If the notch of the balloon was rapidly expanded, suggesting a tear at the stenotic site, dilation is immediately stopped and the balloon was deflated, and then the endoscope and deflated balloon were removed. 
1 severity of the stricture. A single balloon was used in each EBD session. When the endoscope

2 could be passed through the site of the mucosal defect, a balloon of $18-20 \mathrm{~mm}$ was used.

3 When the stricture was less than $10 \mathrm{~mm}$ in diameter and larger than $5 \mathrm{~mm}$, a $15-18 \mathrm{~mm}$

4 balloon was used. When the stricture was less than $5 \mathrm{~mm}$ in diameter and larger than $2-3 \mathrm{~mm}$,

5 a 12-15 mm balloon was used. When the stricture was a pinhole stricture, a 10-12 mm

6 balloon was used. We did not perform preventive EBD when the luminal diameter was

7 estimated to be greater than $20 \mathrm{~mm}$ because the diameter of the lumen would have been

8 greater than that of the fully expanded balloon.

In this study, we defined the EBD procedure performed immediately after EMR/ESD as

10 "preventive EBD" and that after the development of post-EMR/ESD cicatricial stricture as

11 “conventional EBD”.

Protocol of the preventive EBD and conventional EBD

Preventive EBD was commenced within one week after the EMR/ESD and repeated

weekly until the complete healing of mucosal defect was observed (Fig 1). Patients consumed a regular diet during the period of mucosal healing and weekly preventive EBD.

If the post-EMR/ESD mucosal defects became scarred with stricture despite repeated preventive EBD, conventional EBD was given repeatedly until the stricture was completely resolved. The time interval of conventional EBD depended on patients' symptom such as dysphagea (usually 2 to 4 weeks). The strategy of conventional EBD has not been changed

20 throughout this study period, therefore, the time interval of conventional EBD is not different 21 between two groups.

\section{Definition of the stricture}

"Stricture" was defined when a standard 11-mm-diameter endoscope (Q240, 1T240;

24 Olympus Optical Co. Ltd., Tokyo, Japan) could not be passed through the site, or when the patients complaint of dysphagea. Whereas, "complete resolution of the stricture" was defined 
1 when a standard diameter endoscope could be passed through the site, and patients' symptom

2 of dysphagia were completely relieved.

In each EBD sessions in all cases, diameter of stricture was measured by comparing with the diameter of inflated balloon under the fluoroscopic monitoring, and it was classed into 3 groups: $\leq 2 \mathrm{~mm} ;>2 \mathrm{~mm}$ and $\leq 5 \mathrm{~mm} ;>5 \mathrm{~mm}$. The duration required for resolving the stricture was defined as the time interval between the day when the stricture was first observed and the day of complete resolution.

\section{Evaluation of preventive EBD}

The efficacy of preventive EBD was evaluated retrospectively by comparing the following three points between the patients with preventive EBD and those without it (Fig 2);

11 the occurrence rate of stricture, the diameter of stricture, and the duration required for

12 resolving the stricture by repeated conventional EBD.

\section{Statistical analysis}

14 Fisher's exact test, or its extension when there were more than two categories, was used for categorical variables and the Mann-Whitney $U$ test was used for continuous variables. was considered significant. All statistical analyses were performed using the Dr. SPSS II

18 Statistics software package (SPSS Japan Inc., Tokyo, Japan).

\section{RESULTS}

\section{Patient background}

Among the 64 patients with mucosal defects greater than three-fourths of the circumference of the esophagus after EMR/ESD, three patients did not attend follow-up consultations, 17 received additional treatment for primary lesions (chemoradiation for deep 
1 invasion of the carcinoma or EMR/ESD for local recurrence and incomplete resection), and

2 three underwent surgical resection for metachronous gastric cancer immediately after

$3 \mathrm{EMR} / \mathrm{ESD}$. We excluded these 23 patients because additional treatments had the potential to

4 make the stricture worse. Finally, we used data from 41 lesions in 41 patients to evaluate the

5 efficacy of the preventive EBD.

6 Thirty-six lesions were removed by EMR and five lesions were removed by ESD

7 procedure. A histopathological diagnosis of squamous cell carcinoma was found in all lesions

8 and 40 lesions were mucosal cancers but one submucosal cancer.

Of the 41 patients, 29 underwent preventive EBD and 12 did not. There were no

10 statistical differences in the characteristics of the patients and the mucosal defects except for

11 the endoscopic resection method between patients who underwent preventive EBD and those

12 who did not. Because the ESD was recently established technique, there are no patients

13 treated by ESD in the historical control group. Although the difference was not statistically

14 significant, the rate of circumferential resections tended to be greater in conventional EBD

15 group [10/29 (34\%) vs 6/12 (50\%), $p=0.49]$. (Table 1$)$

\section{Profile of preventive EBD sessions}

17 Among the 29 patients who underwent preventive EBD, the median number of

18 preventive EBD sessions was six (range, 3-9) and the period of preventive EBD was 45 days

19 (range, 16-65). (Table 3)

\section{Efficacy of preventive EBD}

The number of patients who developed stricture after EMR/ESD was significantly

22 lower in patients who were given preventive EBD than those who were not given preventive $23 \operatorname{EBD}[12 / 29(59 \%)$ vs 11/12 (92\%), p=0.04] (Table 2). 
1 who were given preventive EBD than those who were not given preventive EBD $[(\leq 2 \mathrm{~mm}$;

$2>2 \mathrm{~mm}$ and $\leq 5 \mathrm{~mm} ;>5 \mathrm{~mm})=(1 ; 2 ; 14)$ vs $(4 ; 4 ; 3), \mathrm{p}=0.01]($ Table 2$)$.

3 The number of days to development of stricture was 23 days (21-49) in patients

4 without preventive EBD. Similarly, in patients who were given preventive EBD, tendency of

5 stricture development was observed within 2 weeks after EMR/ESD. However, preventive

6 EBD could prevent the patients' symptom such as dysphagea because dilation was performed

7 at short intervals (once a week) in all patients. Therefore, no patients suffered from

8 dysphagea during the preventive EBD period in this study. Since the patients with preventive

9 EBD complained the symptom of dysphagia after the completion of weekly preventive EBD,

10 the number of days to development of stricture was 51 days (30-72). It was significantly

11 longer in patients who underwent preventive EBD than those who did not $(p<0.001)$.

12 Seventeen patients with preventive EBD and 11 patients without preventive EBD

13 developed esophageal stricture. Then, they were given conventional EBD repeatedly until the

14 stricture was completely relieved. Among them, the duration required conventional EBD was significantly shorter in patients given preventive EBD than in those not given it (29 days vs 78 days; $\mathrm{p}=0.04)$. The number of conventional EBD sessions was smaller in patients with

17 preventive EBD than in those without it, although the difference was not statistically

18 significant (2 times vs 4.5 times; $\mathrm{p}=0.5$ ) (Table 3 ).

19 The number of total EBD sessions was greater in patients with preventive EBD than in 20 those without it, however, the difference was not statistically significant ( 8 times vs 4.5 times; $21 \mathrm{p}=0.42)($ Table 3$)$.

\section{Safety of EBD procedure}

Among a total of 166 preventive EBD sessions for 29 patients, no complication occurred during the procedure (complication rate of preventive EBD: 0\%). Among a total of 189 conventional EBD sessions for 28 patients, a perforation was occurred in one 
1 conventional EBD session in one patient (0.5\% per total conventional EBD sessions, $3.6 \%$

2 per patient). The patient was immediately hospitalized and administered intravenous

3 antibiotics. The patient had no symptoms or signs of mediastinitis. The fasting period was

4 three days and hospital stay was only one week after causal EBD. No other major

5 complication occurred.

\section{Clinical course of all patients after EMR/ESD}

Follow up period was calculated between the day of EMR/ESD and the day of patients'

8 final visit. After the complete resolution of stricture, endoscopic examination was performed

9 every 6 months in all patients. Median follow up period of all patients was 84 months. There

10 were no patients who suffered from dysphagea due to the recurrence of stricture.

11 Risk of stricture

\section{Risk factors for stricture among patients with preventive EBD}

The method of endoscopic resection (EMR) and the longitudinal length of mucosal defect (>30 $\mathrm{mm}$ in length) were significantly associated with the increased risk for development of stricture by multivariate analysis (Odds ratio: 20.8, 95\% CI 1.3-328.9 and 12.7, 95\%CI 1.3-126.9, respectively). Circumferential mucosal defects showed a higher rate of stricture than semi-circumferential mucosal defects; however, the difference was not statistically significant (Odds ratio: 3.0, 95\%CI 0.2-40.5). (Table 4)

\section{DISCUSSION}

Technically, extended esophageal mucosal resection could be performed. However, the development of the esophageal stricture is one of the most important problems to be solved.

23 To date, there are no well-established methods to prevent the stricture after EMR/ESD. If we 
1 can prevent the development of the stricture after EMR/ESD by preventive EBD, the ability

2 of the patients' oral intake would be dramatically improved.

In this study, we demonstrated that the preventive EBD reduced the incidence of esophageal stricture in patients who underwent an extensive EMR/ESD. In our preventive EBD protocol, EBD was performed once a week for about 6 weeks [median; 44 days (16-65 days)] until the mucosal defect completely developed scar. Because of this strategy, the number of EBD sessions tended to be greater. Although it did not reach statistical significance $(\mathrm{p}=0.42)$, the total number of EBD sessions was nearly twice as high compared to the conventional EBD group (8.0 vs 4.5). However, the narrowest diameter of stricture was significantly mild in the preventive EBD group compared to the group without it (Table 2), while $60 \%$ of the patients in the preventive EBD group develop stricture. Clinically, the severity of the stricture is very important, because it critically affects the oral intake condition. Furthermore, the preventive EBD shortened the period to relieve the stricture even when the stricture was developed. These data indicated that the preventive EBD was a beneficial method, and thus should be considered to perform for the patients who underwent extensive EMR/ESD as a supportive treatment. Perforation and massive bleeding were the most severe complications during the EBD procedure. However, there was no complication associated with preventive EBD procedure in this study. Thus, we could conclude that the preventive EBD was a feasible procedure. Not to develop perforation, we carefully performed preventive EBD under fluoroscopic monitoring, to confirm with both of the size of the stricture and the inflated balloon. When patients complained of pain or when the balloon expanded exponentially, we stopped dilating the balloon immediately not to develop deep tear or perforation. groups; the rate of circumferential resections [10/29 (34\%) vs 6/12 (50\%), $p=0.49]$ and the 
1 rate of ESD resections [5/29 (17\%) vs 0/12 (0\%), $p<0.001]$. Although the difference of the

2 rate of circumferential resections was not statistically significant, the possibility that the

3 results of this study might be influenced by the difference cannot be denied. However, the

4 "circumferential resection" and "non-circumferential resection" were not associated with the

5 risk of development of stricture by the multivariate analysis even in the preventive EBD

6 group. Therefore, it seemed that the imbalance about the rate of circumferential resection

7 between two groups was not a major problem. As for the different rate of ESD resections,

8 there are no patients treated by ESD in the historical control group because the ESD was

9 recently established technique. These imbalances between two groups are unavoidable

10 limitations of the retrospective review with small sample size.

11 The rate for stricture was lower in patients who underwent ESD than those who received EMR [1/5 (20.0\%) vs 16/24 (66.7\%), p=0.03]. Although the reason for this difference is unknown, one possibility is that the potent cautery effect of EMR compared to that of ESD might cause more severe submucosal injury resulting in an increased risk for development of stricture. [15] Clarification of the precise mechanisms for developing stricture after EMR/ESD is warranted in future studies. In addition, the difference of rate for stricture between two groups might be influenced by the lower rate for stricture in ESD patients. However, there are no ESD patients who did not undergo preventive EBD, it is therefore impossible to evaluate the real influence from ESD patients for the results of this 20 study.

Temporary stent placement may also be a promising strategy for preventing post-EMR/ESD stricture. Self-expandable removable stents or biodegradable stents have been reported to be useful for the treatment of benign stricture such as anastomotic stricture and cicatricial stricture by esophagitis. [16] However, there has been no report on the use of 
1 biodegradable stents have been reportedly applied for prevention of the post-EMR/ESD

2 stricture, a small number of patients, short-term follow-up periods, and a high frequency of

3 stent migration obscured its usefulness. [17, 18] Thus, further evaluation of these methods is

4 required to compare their usefulness with the EBD.

5 The multivariate analysis in patients with preventive EBD revealed that the longer

6 longitudinal mucosal defects $(>30 \mathrm{~mm})$ was the significant risk factor for development of the

7 stricture; on the other hand, the circumferential mucosal defect was not a significant risk

8 factor. To avoid the treatment induced esophageal stricture, these data are informative when

9 we select the treatment modalities for the extended esophageal cancer; such as EMR/ESD,

10 chemoradiotherapy, radiotherapy or surgical resection. If patients prefer the remaining the

11 sufficient ability of oral intake, extensive EMR/ESD should not be indicated, because the

12 long term EBD would be needed and the symptom of dysphagia afflicts the patients.

13 In conclusion, preventive EBD could be a useful and acceptable strategy to reduce the

14 incidence of post-EMR/ESD stricture. Because there is no other effective method to prevent

15 stricture after extensive EMR/ESD at present, preventive EBD should be considered for all

16 patients who undergo extensive EMR/ESD. While almost $60 \%$ of patient developed stricture

17 despite the preventive EBD, the severity of the stricture was clearly reduced even when the

18 stricture was developed. Since the number of patients in this study is rather small, and

19 moreover, this was the retrospective study, a prospective study with a large number of cases

20 is required to confirm the effectiveness of preventive EBD procedure for the prevention of

21 post-EMR/ESD stricture in patients with early stage esophageal cancer. 


\section{REFERENCES}

21 Inoue $\mathrm{H}$, Tani M, Nagai K, et al. Treatment of esophageal and gastric tumors.

$3 \quad$ Endoscopy. 1999; 31: 47-55.

42 Fujita H, Sueyoshi S, Yamana H, et al. Optimum treatment strategy for superficial

5 esophageal cancer: endoscopic mucosal resection versus radical esophagectomy. World

$6 \quad$ J Surg. 2001; 25: 424-31.

73 Satodate H, Inoue H, Yoshida T, et al. Circumferential EMR of carcinoma arising in

$8 \quad$ Barrett's esophagus: case report. Gastrointest Endosc. 2003; 58: 288-92.

94 Seewald S, Akaraviputh T, Seitz U, et al. Circumferential EMR and complete removal

10 of Barrett's epithelium: a new approach to management of Barrett's esophagus

11 containing high-grade intraepithelial neoplasia and intramucosal carcinoma.

$12 \quad$ Gastrointest Endosc. 2003; 57: 854-9.

135 Soetikno R, Kaltenbach T, Yeh R, et al. Endoscopic mucosal resection for early cancers 14 of the upper gastrointestinal tract. J Clin Oncol. 2005; 23: 4490-8.

156 Fujishiro M, Yahagi N, Kakushima N, et al. En bloc resection of a large semicircular 16 esophageal cancer by endoscopic submucosal dissection. Surg Laparosc Endosc 17 Percutan Tech. 2006; 16: 237-41.

187 Fujishiro M, Yahagi N, Kakushima N, et al. Endoscopic submucosal dissection of 19 esophageal squamous cell neoplasms. Clin Gastroenterol Hepatol 2006;4:688-94.

208 Chiu YC, Hsu CC, Chiu KW, et al. Factors influencing clinical applications of 21 endoscopic balloon dilation for benign esophageal strictures. Endoscopy. 2004; 36: $22 \quad 595-600$.

239 Kim SH, Lee SO. Circumferential intramural esophageal dissection successfully treated 24 by endoscopic procedure and metal stent insertion. $J$ Gastroenterol. 2005; 40: 1065-9. 
110 Lew RJ, Kochman ML. A review of endoscopic methods of esophageal dilation. J Clin

2

311 Pereira-lima JC, Ramires RP, Zamin I Jr., et al. Endoscopic dilation of benign

4

5

612 Katada C, Muto M, Manabe T, et al. Esophageal stricture after endoscopic mucosal

7 esophageal strictures: Report on 1043 procedures. Am J Gastroenterol. 1999; 94: 1497-501. resection of superficial esophageal lesions. Gastrointest Endosc. 2003; 57: 165-9.

13 Monma K, Sakaki N, Yoshida M. Endoscopic mucosectomy for precise evaluation and treatment of esophageal intraepithelial cancer (in Japanese with English abstract).

Endoscopia Digestiva. 1990; 2: 501-6.

114 Makuuchi H. Endoscopic mucosal resection for early esophageal cancer - Indications 2 and techniques. Digestive Endoscopy. 1996; 8: 175-9.

15 Conio M, Sorbi D, Batts KP, et al. Endoscopic circumferential esophageal 4 mucosectomy in a porcine model: an assessment of technical feasibility, safety, and 5 outcome (short communication). Endoscopy. 2001; 33: 791-4

616 Karbowski M, Schembre D, Kozarek R, et al. Polyflex self-expanding, removable 7 plastic stents: assessment of treatment efficacy and safety in a variety of benign and 8 malignant conditions of the esophagus. Surg Endosc. 2008; 22: 1326-33.

917 Saito Y, Tanaka T, Andoh A, et al. Usefulness of biodegradable stents constructed of 20 poly-l-lactic acid monofilaments in patients with benign esophageal stricture. World $J$ 1 Gastroenterol. 2007; 13: 3977-80.

22 Saito Y, Tanaka T, Andoh A, et al. Novel biodegradable stents for benign esophageal 3 strictures following endoscopic submucosal dissection. Dig Dis Sci. 2008; 53: 330-3. 


\section{FIGURE LEGENDS}

2 Figure 1. A representative case who received preventive EBD after a

3 semi-circumferential ESD.

4 (a) Semi-circumferential mucosal defect immediately after the ESD.

5 (b) Mucosal defect one week after the ESD. The site gradually developed scarring with mild

6 stricture.

7 (c) Mucosal defect one month after the ESD. The site developed scarring furthermore, but the

8 stricture was mild.

9 (d) Post-ESD site two months after the ESD. The complete healing of the post-ESD mucosal

10 defect was observed without stricture. The endoscope could be passed through the site and

11 the patient did not complain of any symptoms associated with esophageal stricture.

12

13 Figure 2. Diagram of patients flow.

14 


\section{Figure 1 (a)}

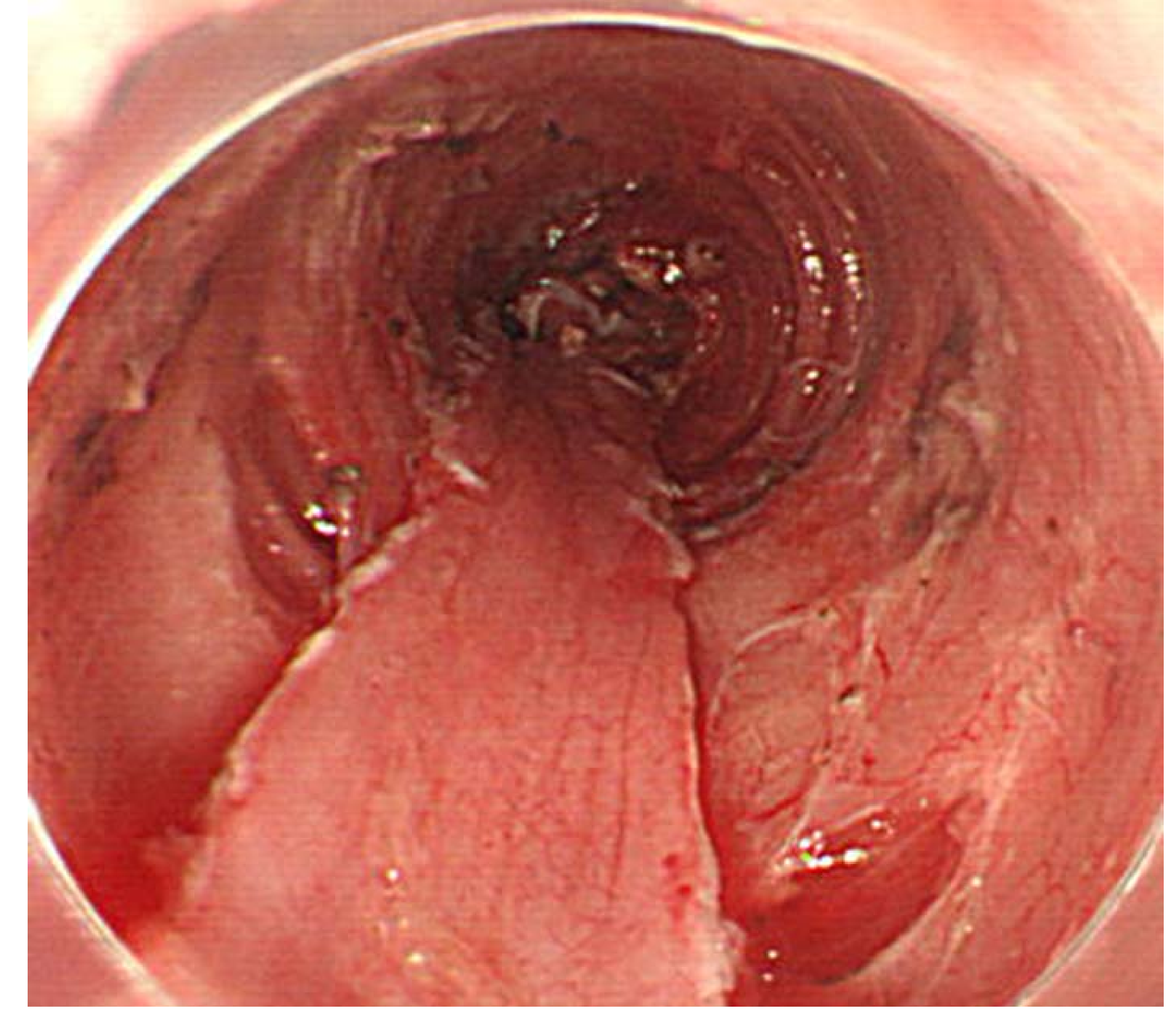




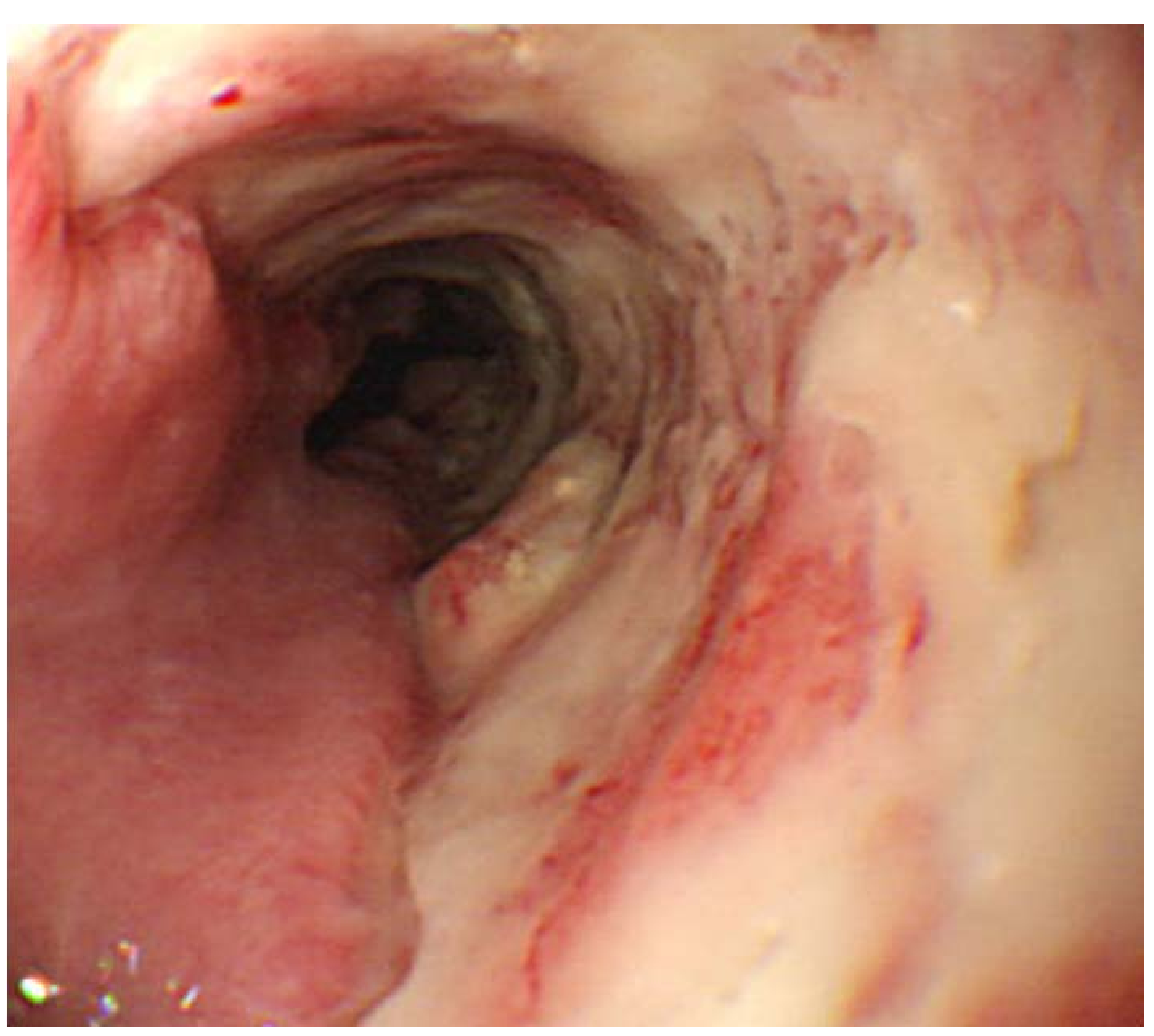


Figure 1 (c)

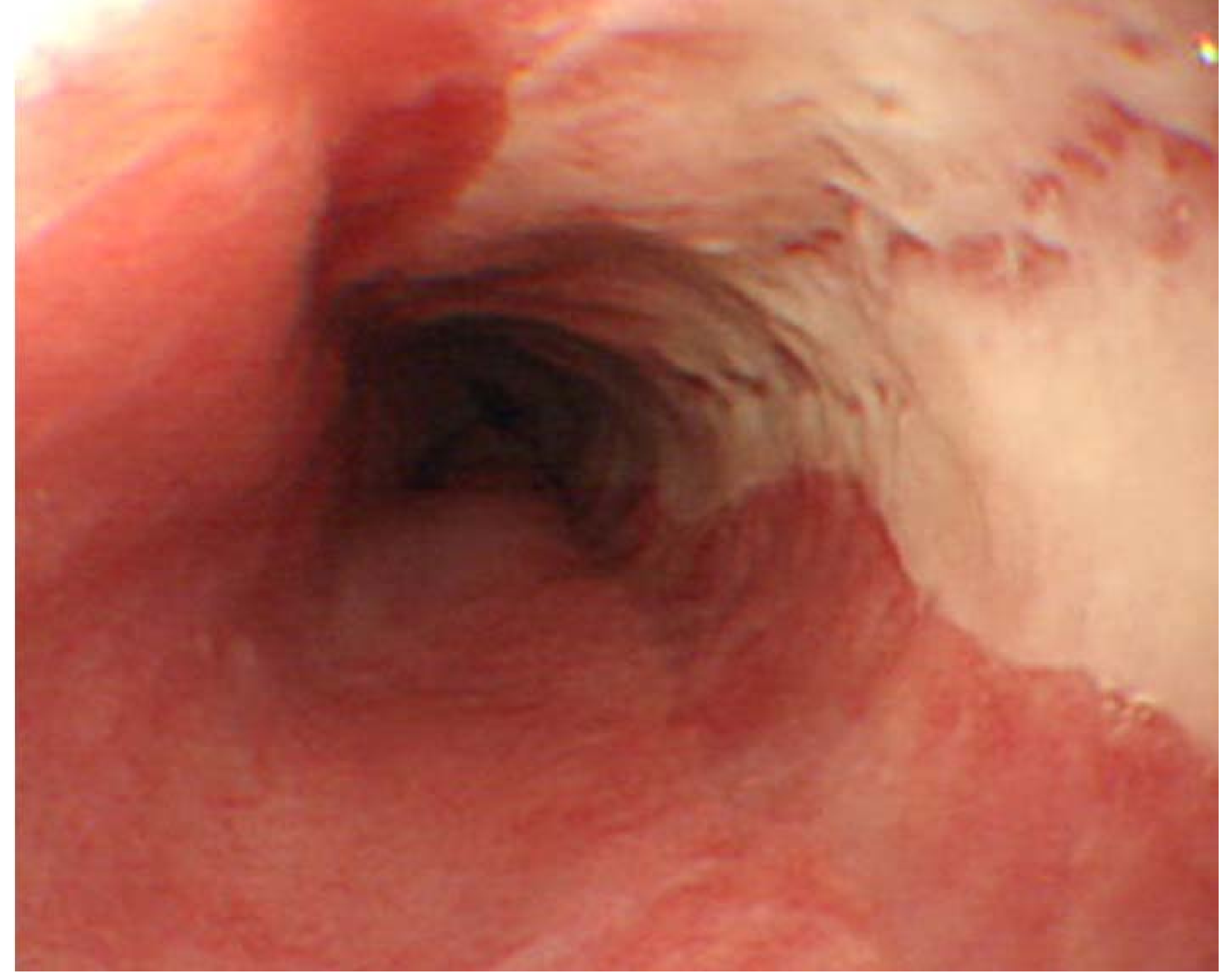




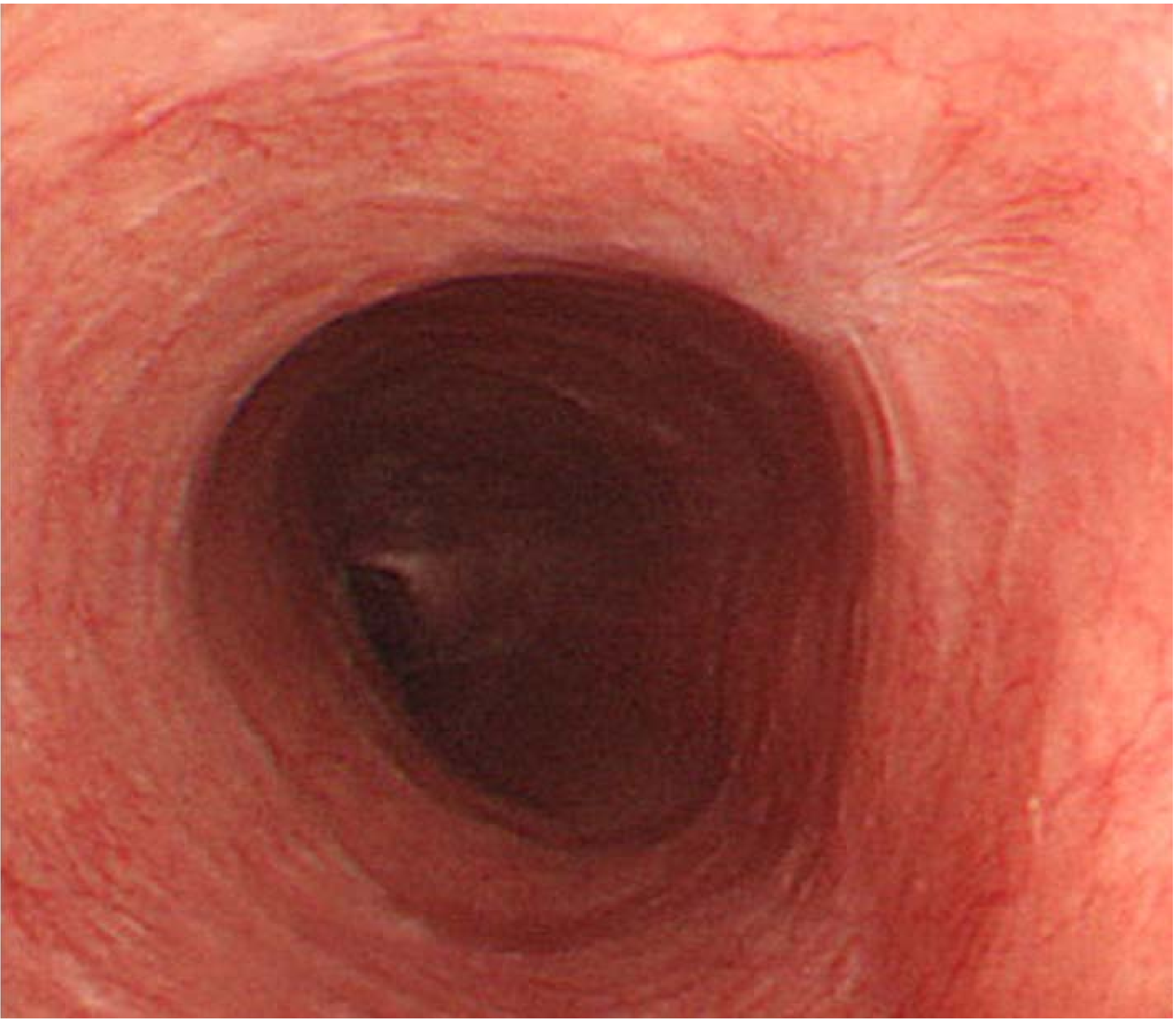


Figure 2

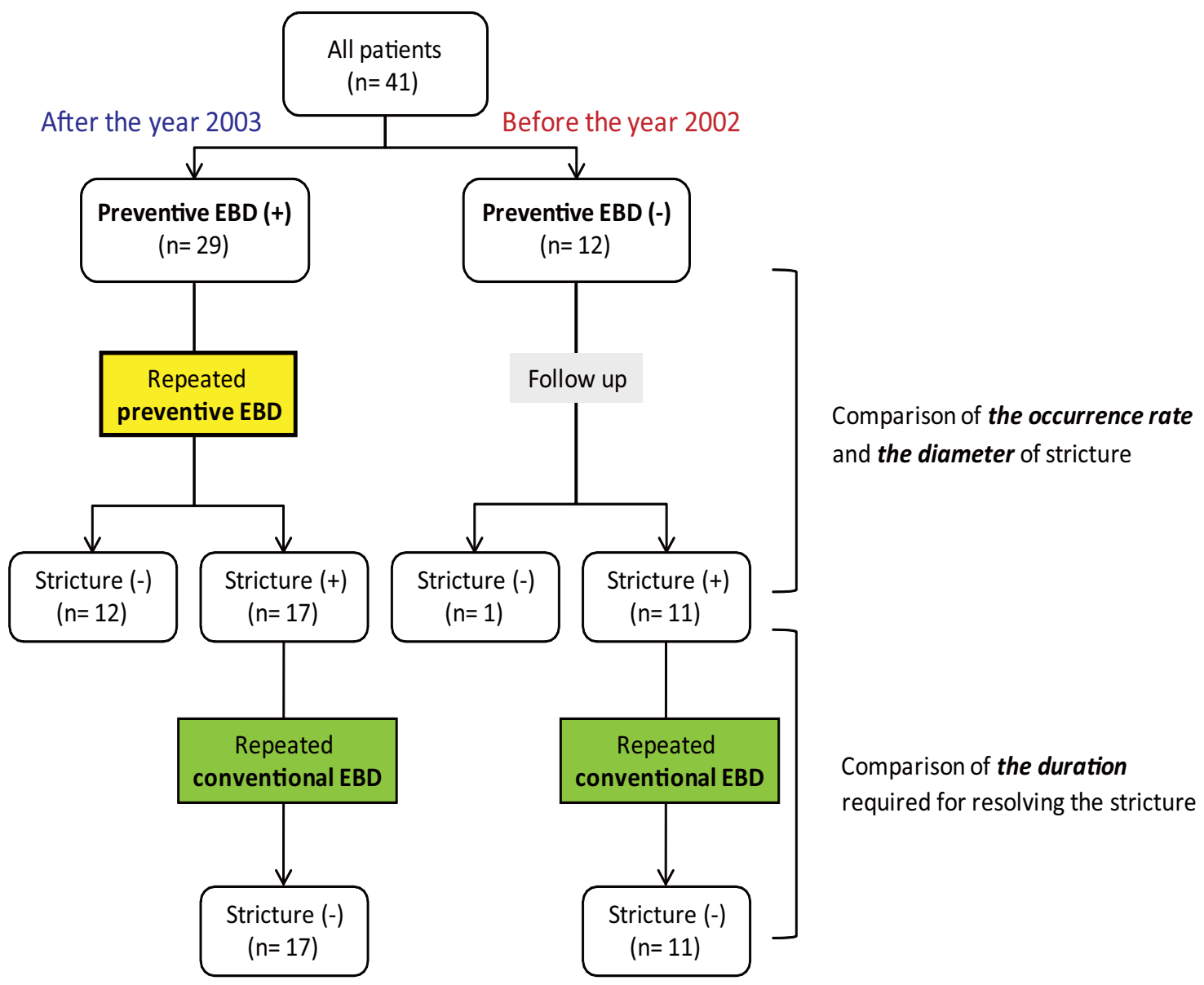


1

Table 1. Comparison of the characteristics of mucosal defects after endoscopic resection in patients with and without preventive EBD

\section{Preventive EBD}

\begin{tabular}{lcccc}
\cline { 3 - 4 } & $\begin{array}{c}(+) \\
\mathbf{n = 2 9}\end{array}$ & $\begin{array}{c}(-) \\
\mathbf{n = 1 2}\end{array}$ & p value \\
\hline Sex & & & \\
& & 28 & 11 & 0.50 \\
& male & 1 & 1 &
\end{tabular}

Age

median (range)

64 years $(50-74) \quad 60$ years $(48-80)$

0.21

Circumference of the lumen

Circumferential

10

6

Semi-circumferential

19

6

Depth of resected lesion

Mucosa

28

12

Submucosa

1

0

0.34

Location

Upper

3

Middle

13

5

0.30

Lower

13

6

Length of mucosal defect

$30 \mathrm{~mm}$ or less

6

more than $30 \mathrm{~mm}$

23

4

8

0.30

median (range)

$40 \mathrm{~mm}(10-110)$

$45 \mathrm{~mm}(20-70)$

0.38

Endoscopic resection procedure 
EMR

24

12

ESD

Number of patients are shown unless specified

EBD: endoscopic balloon dilation, EMR: endoscopic mucosal resection, ESD: endoscopic submucosal dissection 
1

Table 2. Comparison of the occurrence rate and the diameter of esophageal stricture between patients with and without preventive EBD

\begin{tabular}{ccc}
\hline & \multicolumn{2}{c}{ Preventive EBD } \\
\cline { 2 - 3 }
\end{tabular}

Number of patients who developed 17/29 $11 / 12$

stricture

$(59 \%)$

$(92 \%)$

0.04

The narrowest diameter of the stricture

$\begin{array}{lccc}<2 \mathrm{~mm} & 1 / 17 & 4 / 11 & \\ & (6 \%) & (36 \%) & 0.01 \\ 2 \mathrm{~mm}<\text { and }<5 \mathrm{~mm} & 2 / 17 & 4 / 11 & \\ & (12 \%) & (36 \%) & 3 / 11 \\ 5 \mathrm{~mm}< & 14 / 17 & (28 \%) & \end{array}$

Number of patients are shown unless specified

${ }^{\dagger}$ Median (range)

EBD: endoscopic balloon dilation

2 
Table 3. Comparison of the duration and the number of EBD sessions required for resolving the stricture by conventional EBD between patients with and without preventive EBD

\begin{tabular}{ccc}
\hline \multicolumn{3}{c}{ Preventive EBD } \\
\hline$(+)$ & $(-)$ & p value \\
\hline
\end{tabular}

Period of preventive $\mathrm{EBD}^{\dagger}$

Number of days to development

of the stricture ${ }^{\dagger}$

Duration required for resolving

the stricture ${ }^{\dagger}$

Number of preventive EBD

sessions $^{\dagger}$

Number of conventional EBD

sessions $^{\dagger}$

Number of total EBD sessions ${ }^{\dagger}$

8.0 sessions

(3-29)

$17 / 17$

$(100 \%)$

(16-65)

51 days

(30-72)

(15-169)

6.0 sessions

(3-9)

2.0 sessions

(2-20)

Number of patients whose

stricture was relieved

$$
(100 \%)
$$

$(-)$

23 days

(21-49)

$<0.001$

78 days

(8-1093)

0.04

$(-)$

$(-)$

$(2-35)$

4.5 sessions

(0-35)

0.42
0.5

1

Number of patients are shown unless specified

${ }^{\dagger}$ Median (range)

EBD: endoscopic balloon dilation 
Table 4. Predictive factors for development of stricture after endoscopic resection in patients who received preventive EBD

\section{Odds Ratio $(95 \% \mathrm{Cl}) \quad$ p value}

Method of Endoscopic resection

ESD

1.0 (reference)

EMR

$20.8(1.3-328.9)$

0.03

Longitudinal length of mucosal defect involving over three-fourth of the esophageal circumference

$\leq 30 \mathrm{~mm} \quad 1.0$ (reference)

$>30 \mathrm{~mm}$

0.03

$12.7(1.3-126.9)$

Circumference of mucosal defect
Semi-circumferential
1.0 (reference)
Circumferential
$3.0(0.2-40.5)$

EBD: endoscopic balloon dilation 